\title{
Effect of routine pre-operative urethral catheterization of women undergoing minor gynaecological surgeries on urinary symptoms and urinary infections: a randomized control study
}

\author{
Mohannad Abu Faza ${ }^{1}$, Ibrahim A. Abdelazim ${ }^{1,2}$, Amr A. Aziz Khalifa ${ }^{2}$, Hossam S. Othman ${ }^{1}$, \\ Dareen A. Alsharif ${ }^{1}$
}

${ }^{1}$ Department of Obstetrics and Gynaecology, Ahmadi Hospital, Kuwait
${ }^{2}$ Department of Obstetrics and Gynecology, Ain Shams University, Egyp

Received: 30 May 2016

Accepted: 01 July 2016

*Correspondence:

Dr. Ibrahim A. Abdelazim,

E-mail: dr.ibrahimanwar@gmail.com

Copyright: ( ) the author(s), publisher and licensee Medip Academy. This is an open-access article distributed under the terms of the Creative Commons Attribution Non-Commercial License, which permits unrestricted non-commercial use, distribution, and reproduction in any medium, provided the original work is properly cited.

\begin{abstract}
Background: The prevalence of urinary tract infection increases in young sexually active women, and women with previous UTI. Routine urethral catheterization performed for bladder evacuation before minor gynecological procedures and it is not clear whether this routine urethral catheterization associated with increased incidence of bacteriuria or UTIs or not. This study designed to detect the effect of routine uretheral catheterization for women undergoing minor gynecological surgeries on urinary symptoms and urinary infections.

Methods: Two hundred and forty women infertile women scheduled for uterine assessment by diagnostic hysteroscopy before in-vitro fertilization in assisted reproduction unit of Ahmadi Hospital, Kuwait Oil Company were included in this study. Participants were randomized into; group I (catheterized group) and group II (non-catheterized group). Participants' urine samples compared pre-operatively and post-operatively and they asked to complete about their pre and post-operative urinary symptoms.

Results: Post-operative dysuria, frequency and urgency were significantly higher in catheterized group (22 (18.33\%), $26(21.66 \%)$ and $18(15 \%)$; respectively) compared to non- catheterized group [5 (4.16\%), $7(5.83 \%)$ and $4(3.33 \%)$; respectively]. Relative risk of dysuria, frequency and urgency after catheterization were 4.4, 3.7 and 4.5; respectively (95\% CI; 1.7-11.2, 1.67-8.22 and 1.56-12.9; respectively). Asymptomatic bacteriuria, UTIs and subsequent need for antimicrobial therapy were also significantly high in catheterized group [15 (12.5\%), 18 (15\%) and $18(15 \%)$; respectively) compared to non-catheterized group (3 (2.5\%), $2(1.96 \%)$ and $2(1.96 \%)$; respectively]. Relative risk of asymptomatic bacteriuria and UTIs after catheterization in women undergoing minor gynecological procedures were 5 and 9; respectively (95\%CI; 1.48-16.8 and 2.1-37.9).

Conclusions: Catheterization in women undergoing minor gynecological surgery was associated with increased risk of dysuria, frequency, urgency, ASB, UTIs and subsequent antimicrobial therapy. Surgeons should revise the practice of routine preoperative catheterization for women undergoing minor gynecological procedures.
\end{abstract}

Keywords: Urethral, Catheterization, Gynecological, Urinary, Complications

\section{INTRODUCTION}

Urinary tract infections (UTIs) increases in young sexually active women, and women with previous UTI. ${ }^{1-3}$ UTIs is the most common indication for antimicrobial use in hospitals. ${ }^{1}$ approximately $80 \%$ of UTIs are catheter- associated. $^{4,5}$ Urine cultures usually done when a significant suspicion for a UTIs, based on patient symptoms and presence of leukocyte esterase and nitrites that suggest the presence of leucocytes and gramnegative organism's respectively. ${ }^{6-8}$ 
Urine Cultures are only recommended with symptoms of UTIs or change in urine color, odor or turbidity, and in urologic surgery, when a urinary catheter is placed or changed. 8,9

Presence of bacteria in the urine may indicate; specimen contamination; UTIs or asymptomatic bacteriuria (ASB). ${ }^{10,11}$ Specimen contamination should always be considered, particularly in female patients with high numbers of squamous cells on the urinalysis. ${ }^{10-12}$

The diagnosis of ASB and UTIs should be based on culture of a urine specimen collected in a manner that minimizes contamination. ${ }^{13}$ ASB diagnosed with one bacterial species isolated in a quantitative count $105 / \mathrm{ml}$ in urine sample. ${ }^{14}$ UTIs diagnosed with one bacterial species isolated in quantitative count $\geq 105$ bacteria per ml of voided urine in women with symptoms of UTIs. ${ }^{13-15}$

Preventive guidelines published by the United States centers for disease control and prevention suggest that avoiding catheterization is not often possible but should be considered. ${ }^{4,5}$

Routine catheterization performed for bladder evacuation before minor gynecological procedures because it is difficult to bimanually evaluate the uterus or to catch uterine cervix with full bladder. ${ }^{6}$ It is not clear whether this routine urethral catheterization associated with increased incidence of bacteriuria or UTIs or not. ${ }^{16}$

In addition; women can be informed to void urine normally and evacuate their bladders before minor gynaecological surgery to avoid routine catheterization. ${ }^{13}$

This randomized controlled study designed to detect the effect of routine urethral catheterization for women undergoing minor gynaecological surgeries on urinary symptoms and urinary infections.

\section{METHODS}

This randomized study conducted during the period between February 2014 and February 2015. The study protocol approved by the local ethical research committee of Ahmadi Hospital, Kuwait Oil Company (KOC), Kuwait. All participating women signed informed written consent after thorough explanation of the purpose and procedure of the study.

Two hundred and forty women infertile women scheduled for uterine cavity assessment by diagnostic hysteroscopy before in-vitro fertilization in assisted reproduction unit of Ahmadi hospital. Diagnostic hysteroscopy scheduled for studied women postmenstrual in the early-mid follicular phase of the menstrual cycle, 1-3 months before starting the in-vitro fertilization (IVF) treatment.

Recruited eligible women randomized into; group I (catheterized group), including women who had urinary catheterization once to evacuate the bladder and group II (non-catheterized group), including women who voided urine spontaneously and had no urinary catheterization before hysteroscopy (Figure 1).

Urinary catheterization was done by the surgeon himself, under general anesthesia after sterilization and toweling, the vulva was separated and the external urethral opening was cleaned by piece of cotton soaked with plain water, then Nelaton's catheter size 12-14 Fg was passed to the urinary bladder under aseptic condition to evacuate the bladder once and removed.

According to hospital protocol diagnostic hysteroscopy is usually done by the registrar who has master degree in obstetrics and gynaecology supervised by consultant who has master and MD degree in obstetrics and gynaecology.

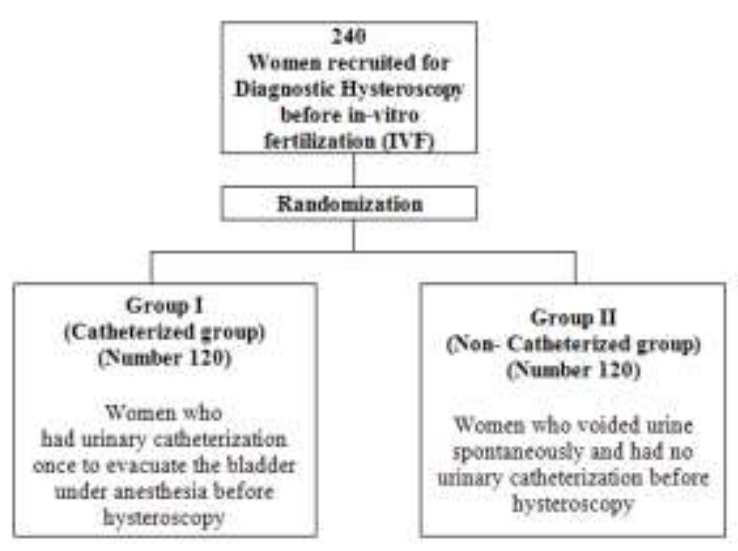

Figure 1: Flow diagram of the studied women.

Women with urinary tract known anomalies or stones and women with positive urinary symptoms (dysuria, frequency, lower abdominal tenderness or urgency) or positive UTIs with in last 6 months before inclusion excluded from this study.

Randomization performed using a computer-generated randomization system. A plan of interventions sealed in closed envelops, numbered in accordance with the randomization tables and opened the senior nurse officer (SNO) of the gynaecological ward before transfer of the studied women to operative room. Packing, sealing and numbering performed by two independent doctors other than the investigator.

Routine pre-operative cultures urine samples taken from studied women compared with post-operative urine cultures of women with positive urinary symptoms and studied women were asked about their pre and postoperative urinary symptoms (dysuria, frequency, lower abdominal tenderness or urgency).

Urine cultures were done for all studied women preoperatively and post-operatively and antimicrobial therapy were prescribed based on positive urinary symptoms and positive cultures. No antimicrobial therapy for women with ASB. ${ }^{2,17}$ 
ASB diagnosed with one bacterial species isolated in a quantitative count $105 / \mathrm{ml}$ in urine sample. UTIs diagnosed with one bacterial species isolated in quantitative count $\geq 105$ bacteria per $\mathrm{ml}$ of voided urine in women with symptoms of UTIs. ${ }^{13-15}$ The midstream, clean-catch urine collection technique remains the most used method of specimen collection. Women instructed to separate their legs apart, to clean the inner folds of the labia and urethral opening by plain water, then start to void and catch midstream urine for culture to decrease contamination of the specimen by introitus bacteria. ${ }^{2,17}$

Primary outcome measures; symptoms suggestive of UTIs, and post-operative diagnosed by urine cultures.

\section{Sample size justification}

Sample size was calculated using $G^{*}$ power software version 3.17 for sample size calculation (*Heinrich Heine Universität; Düsseldorf; Germany), setting the $\alpha$-error probability at 0.05 , power ( $1-\beta$ error probability) at 0.95 $\%$ and effective sample size $(\mathrm{w})$ at 0.3 . The effective size (w) was calculated as follows:

$$
\mathrm{W}=\sqrt{x^{2}+N}
$$

Where $\mathrm{x}^{2}$ is the Chi-square test and

$\mathrm{N}$ is the total sample size.

240 women were studied (220 women to produce statistically accepted figure and 20 women as calculated $5 \%$ drop rate).

\section{Statistical analysis}

Data were collected, tabulated then statistically analysed using the Statistical Package for Social Science (SPSS) (Chicago, IL, USA). Numerical variables were presented as mean and standard deviation $( \pm \mathrm{SD})$, while categorical variables were presented as number and percentage. Student's t-test, used for numeric parametric variables, and Chi-square (x2) test for categorical variables analysis. $\mathrm{P}$ value $<0.05$ was considered significant.

\section{RESULTS}

There was no significant difference between group I (catheterized group) and group II (non- catheterized group) regarding; mean age $(27.12 \pm 5.2$ versus $28.88 \pm 5.9$ years; respectively), mean BMI $(21.81 \pm 4.2$ versus $22.1 \pm 5.1$; respectively) and duration of diagnostic hysteroscopic $(8.3 \pm 2.7$ versus $7.5 \pm 1.5$ minutes; respectively) (Table 1$)$.

Table 1: Demographic data of two studied groups.

\begin{tabular}{|c|c|c|c|}
\hline Variables & $\begin{array}{l}\text { Group I } \\
\text { catheterized } \\
\text { group } \\
\text { (number } \\
\text { 120) }\end{array}$ & $\begin{array}{l}\text { Group II } \\
\text { non- } \\
\text { catheterized } \\
\text { group } \\
\text { (number } \\
120 \text { ) }\end{array}$ & $\begin{array}{l}\text { P value } \\
\text { ( } 95 \% \\
\text { confidence } \\
\text { interval) }\end{array}$ \\
\hline Age (years) & $27.12 \pm 5.2$ & $28.88 \pm 5.9$ & $\begin{array}{l}0.9(3.16,- \\
1.76,-0.35)\end{array}$ \\
\hline BMI $\left(\mathrm{kg} / \mathrm{m}^{2}\right)$ & $21.81 \pm 4.2$ & $22.1 \pm 5.1$ & $\begin{array}{l}0.98(-1.47 \\
-0.29,0.89)\end{array}$ \\
\hline $\begin{array}{l}\text { Duration of } \\
\text { the } \\
\text { diagnostic } \\
\text { hysteroscopy } \\
\text { (minutes) }\end{array}$ & $8.3 \pm 2.7$ & $7.5 \pm 1.5$ & $\begin{array}{l}0.0(0.270 \\
0.8,1.32)\end{array}$ \\
\hline
\end{tabular}

Analysis done using independent student's t-test; BMI: body mass index [calculated as weight $(\mathrm{kg})$ divided by squared height (m2)]; Data presented as mean \pm SD (standard deviation); $\mathrm{P}$ value $>0.05$ considered insignificant difference.

Table 2: Postoperative urinary symptoms, asymptomatic bacteriuria and urine cultures in studied women.

\begin{tabular}{|llll|}
\hline Variable & $\begin{array}{l}\text { Group I } \\
\text { catheterized group } \\
\text { (number 120) }\end{array}$ & $\begin{array}{l}\text { Group II } \\
\text { non- catheterived } \\
\text { group (number } \\
120)\end{array}$ & $\begin{array}{l}\text { P value; relative risk } \\
95 \% \text { confidence } \\
\text { interval }\end{array}$ \\
\hline Dysuria & $22(18.33 \%)$ & $5(4.16 \%)$ & $0.001 ; 4.4(1.7-11.2)$ \\
\hline Frequency & $26(21.66 \%)$ & $7(5.83 \%)$ & $0.001 ; 3.7(1.67-8.22)$ \\
\hline Lower abdominal tenderness & $22(18.33 \%)$ & $12(10 \%)$ & $0.1 ; 1.8(0.9-3.5)$ \\
\hline Urgency & $18(15 \%)$ & $4(3.33 \%)$ & $0.004 ; 4.5(1.56-12.9)$ \\
\hline $\begin{array}{l}\text { Asymptomatic bacteriuria (quantitative count } \\
10^{2} \text { ml/ml of one bacterial species) }\end{array}$ & $15(12.5 \%)$ & $3(2.5 \%)$ & $0.006 ; 5(1.48-16.8)$ \\
\hline $\begin{array}{l}\text { UTIs }\left(10^{5} \text { bacteria/ml of voided urine in }\right. \\
\text { women with symptoms of UTIs) }\end{array}$ & $18(15 \%)$ & $2(1.96 \%)$ & $0.0005 ; 9(2.1-37.9)$ \\
\hline Antimicrobial therapy & $18(15 \%)$ & $2(1.96 \%)$ & $0.0005 ; 9(2.1-37.9)$ \\
\hline
\end{tabular}

Analysis done using Chi-square test (X2); data presented as number and percentage; $\mathrm{P}$ value $<0.05$ considered significant difference; UTIs: urinary tract infections. 
Post-operative dysuria, frequency and urgency were significantly high in catheterized group [22 (18.33\%), 26 $(21.66 \%)$ and $18(15 \%)$; respectively] compared to noncatheterized group [5 (4.16\%), 7 (5.83\%) and 4 (3.33\%); respectively].

Relative risk of dysuria, frequency and urgency after catheterization were 4.4, 3.7 and 4.5; respectively (95\% CI; 1.7-11.2, 1.67-8.22 and 1.56-12.9; respectively) (Table 2).

Asymptomatic bacteriuria, UTIs and subsequent need for antimicrobial therapy were also significantly high in catheterized group [15 (12.5\%), 18 (15\%) and 18 (15\%); respectively] compared to non-catheterized group [3 (2.5\%), $2(1.96 \%)$ and $2(1.96 \%)$; respectively]. Relative risk of asymptomatic bacteriuria and UTIs after catheterization in women undergoing minor gynaecological procedures were 5 and 9; respectively (95\% CI; 1.48-16.8 and 2.1-37.9) (Table 2).

\section{DISCUSSION}

Preventive guidelines published by the United States Centers for Disease Control and Prevention suggest that avoiding catheterization is not often possible but should be considered. ${ }^{4,5}$ Routine catheterization performed for bladder evacuation before minor gynecological procedures and it is not clear whether this routine catheterization associated with increased incidence of bacteriuria or UTIs or not. ${ }^{16}$

This randomized controlled study designed to detect the effect of routine urethral catheterization for women undergoing minor gynecological surgeries on urinary symptoms and urinary infections.

In this study, post-operative dysuria, frequency and urgency were significantly high in catheterized group (22 (18.33\%), $26(21.66 \%)$ and $18(15 \%)$; respectively) compared to non- catheterized group [5 (4.16\%), 7 $(5.83 \%)$ and $4(3.33 \%)$; respectively].

Relative risk of dysuria, frequency and urgency after catheterization were $4.4,3.7$ and 4.5 ; respectively (95\% CI; 1.7-11.2, 1.67-8.22 and 1.56-12.9; respectively).

Asymptomatic bacteriuria, UTIs and subsequent need for antimicrobial therapy were also significantly high in catheterized group [15 (12.5\%), 18 (15\%) and $18(15 \%)$; respectively] compared to non-catheterized group (3 (2.5\%), $2(1.96 \%)$ and $2(1.96 \%)$; respectively). Relative risk of asymptomatic bacteriuria and UTIs after catheterization in women undergoing minor gynecological procedures were 5 and 9; respectively (95\% CI; 1.48-16.8 and 2.1-37.9).

Emily et al, studied 200 women undergoing minor gynecological procedures to be catheterized or not catheterized. Patients were blinded and provided preoperative and postoperative urine samples for culture. $^{16}$

In this study relative risk of ASB and UTIs after catheterization were 5 and 9 respectively (95\% CI; 1.48 16.8 and 2.1-37.9), Emily et al, found that there is relative risk of postoperative bacteriuria for catheterized patients about $1.24 .^{16}$

Although, in this study the relative risk of dysuria, frequency and urgency after catheterization were 4.4, 3.7 and 4.5 ; respectively $(95 \% \mathrm{CI}$; 1.7-11.2, 1.67-8.22 and 1.56-12.9; respectively), Emily et al, found the prevalence of postoperative urinary discomfort which was low and similar without any significant difference for both the catheterized $(13 \%)$ and not catheterized $(9 \%)$ women and they did not studied or compare the relative risk of urinary discomfort between two studied groups. ${ }^{16}$

Emily et al concluded that the intervention of preoperative one-time catheterization in minor gynecologic procedures is not associated with increased postoperative bacteriuria nor does it significantly increase postoperative urinary discomfort or pain. ${ }^{16}$

In this study, our finding suggests that even one-time catheterization in women undergoing minor gynecological surgery is associated with increased risk of dysuria, frequency, urgency, ASB, UTIs and subsequent antimicrobial therapy.

Approximately $80 \%$ of UTIs are catheter-associated. ${ }^{4,5}$ In addition; Trautner et al, found that catheter-associated urinary tract infection (CAUTI) is one of the most common hospital-acquired infections and many cases treated as hospital-acquired CAUTI are actually asymptomatic bacteriuria (ABU). ${ }^{13}$

Trivedi, concluded that dilatation and curettage and evacuation of the uterus are the 2 most common minor gynecological procedures and routine urinary catheterization before these procedures is unnecessary. ${ }^{6}$

Surgeons should revise routine preoperative catheterization for women undergoing minor gynecological procedures, simply because women undergoing minor gynecological surgery can void normally and evacuate their bladders to decrease incidence of UTIs and need for antimicrobial therapies.

\section{CONCLUSION}

This study was the first randomized controlled study designed to detect the effect of routine pre-operative urethral catheterization for women undergoing minor gynaecological procedures on urinary symptoms and urinary infections with adequate calculated sample size to produce a statistically acceptable figure. A woman ashamed to answer questions about their urinary symptoms was the only limitation faced during this study. 
Larger studies required to confirm the drawbacks of routine preoperative catheterization for women undergoing minor gynaecological procedures.

\section{ACKNOWLEDGMENTS}

Authors are very grateful to the women participated in this study.

Funding: No funding sources

Conflict of interest: None declared

Ethical approval: The study was approved by the Institutional Ethics Committee

\section{REFERENCES}

1. Lentz G. Glob urinary tract infections in obstetrics and gynecology libr. Women's med, 2009. Available at

http://www.glowm.com/section_view/heading/Urina ry $\% 20$ Tract $\% 20$ Infections $\% 20$ in $\% 20$ Obstetrics $\% 20$ a nd\%20Gynecology/item/118.

2. Nicolle LE. Epidemiology of urinary tract infections. Infect Med. 2001;18:153-62.

3. Foxman B. Epidemiology of urinary tract infections: incidence, morbidity, and economic costs. Am J Med. 2002;113 Suppl:1A:5S.

4. Centers for disease control. Catheter-associated urinary tract infection (CAUTI) event. NHSN Patient Safety Component Manual, 2011. Available at http://www.cdc.gov/nhsn/PDFs/pscManual/7pscCA UTIcurrent.pdf. Accessed on 4 November 2011.

5. Gould C, Umscheid C, Agarwal R, Kuntz G, Pegues D. Healthcare infection control practices advisory committee (HICPAC). Guideline for prevention of catheter-associated urinary tract infections, 2009. Available http://www.cdc.gov/hicpac/pdf/CAUTI/CAUTIguide line2009final.pdf. Accessed on 4 November 2011.

6. Trivedi AN. Catheterization prior to evacuation of uterus and diagnostic curettage. Aust N Z J Obstet Gynaecol. 1999;39(2):191-3.

7. Gupta K, Hooton TM, Naber KG, Wullt B, Colgan $\mathrm{R}$, Miller LG, et al. International clinical practice guidelines for the treatment of acute uncomplicated cystitis and pyelonephritis in women: a 2010 update by the infectious diseases society of America and the European society for microbiology and infectious diseases. Clin Infect Dis. 2011;52(5):e103-120.

8. Hooton TM, Bradley SF, Cardenas DD, Colgan R, Geerlings SE, Rice JC, et al. Diagnosis, prevention, and treatment of catheter-associated urinary tract infection in adults: 2009 international clinical practice guidelines from the infectious diseases society of America. Clin Infect Dis. 2010;50(5):62563.

9. Nicolle LE, Bradley S, Colgan R, Rice Jc, Schaeffer A, Hooton TM. Infectious diseases society of america guidelines for the diagnosis and treatment of asymptomatic bacteriuria in adults. Clin Infect Dis. 2005;40(5):643-54.

10. Lin K, Fajardo K. U.S. preventive services task force. Screening for asymptomatic bacteriuria in adults: evidence for the U.S. preventive services task force reaffirmation recommendation statement. Ann Intern Med. 2008;149(1):W20-4.

11. Trautner BW, Petersen NJ, Hysong SJ, Horwitz D, Kelly PA, Naik AD. Overtreatment of asymptomatic bacteriuria: identifying provider barriers to evidencebased care. Am J Infect Control. 2014;42(6):653-8.

12. Trautner BW, Grigoryan L, Petersen NJ, Hysong S, Cadena J, Patterson JE, et al. Effectiveness of an antimicrobial stewardship approach for urinary catheter-associated asymptomatic bacteriuria. JAMA Intern Med. 2015;175(7):1120-7.

13. Trautner BW, Kelly PA, Petersen N, Hysong S, Kell $\mathrm{H}$, Liao KS, et al. A hospital-site controlled intervention using audit and feedback to implement guidelines concerning inappropriate treatment of catheter-associated asymptomatic bacteriuria. Implement Sci. 2011;22(6):41.

14. Linares LA, Thornton DJ, Strymish J, Baker E, Gupta K. Electronic memorandum decreases unnecessary antimicrobial use for asymptomatic bacteriuria and culture-negative pyuria. Infect Control Hosp Epidemiol. 2011;32(7):644-8.

15. Drekonja DM, Rector TS, Cutting A, Johnson JR. Urinary tract infection in male veterans: treatment patterns and outcomes. JAMA Intern Med. 2013;173(1):62-8.

16. Emily GP, Jeffrey B, Akira WG, Elena L, Victoria M. One-time catheterization in short gynecologic procedures and its effect on bacteriuria. The American College of Obstetricians and Gynecologists. 2015;125(Supp 1). Available at http://journals.lww.com/greenjournal/Abstract/2015/ 05001/One_Time_Catheterization_in_Short_Gyneco logic.13.aspx.

17. Gould CV, Umscheid CA, Agarwal RK, Kuntz G, Pegues DA. Healthcare infection control practices advisory committee. Guideline for prevention of catheter-associated urinary tract infections 2009. Infect Control Hosp Epidemiol. 2010;31(4):319-26.

Cite this article as: Faza MA, Abdelazim IA, Khalifa AAA, Othman HS, Alsharif DA. Effect of routine pre-operative urethral catheterization of women undergoing minor gynaecological surgeries on urinary symptoms and urinary infections: a randomized control study. Int J Reprod Contracept Obstet Gynecol 2016;5:2624-8. 